\title{
The Mode Exploration of Industry-Education Integration of Graduate Education in China
}

\author{
Yuping $\mathrm{Xu}^{1, *}$ Fangyi $\mathrm{Su}^{1}$ and Zhenwen Hong ${ }^{1}$ \\ ${ }^{1}$ School of Transportation Engineering, East China Jiaotong University, Nanchang, Jiangxi 330013, China \\ *Corresponding author.Email:xyp730610@qq.com
}

\begin{abstract}
Graduate education is regarded as an important component of China's innovation driven development strategy. In the era of innovation, how to deepen industry-education integration, accordingly, improving the innovative ability of postgraduates and cultivating high-level innovative talents needed by the country and the industry, is the current goal of Chinese educators. This paper introduces the connotation of industry-education integration, focuses on the analysis of the difficulties encountered in the process of promoting industryeducation integration in China and gives suggestions. It is essential to build a complete system of policies and lows with a comprehensive evaluation system. In addition, the important role of the enterprise should be properly brought into play.
\end{abstract}

Keywords: graduate education, innovation, industry-education integration, mode exploration

\section{INTRODUCTION}

"Develop the country through science and education"has always been an important development strategy of China. Make science and education placed at an important position in economic and social development, boost economic growth and enhance overall national strength by enhancing the country's scientific and technological strength, only in this way, can we accelerate the realization of national prosperity and strength.

As the highest level of higher education in China, graduate education plays an incomparable role in cultivating highlevel talents with excellent innovation ability. Therefore, China attaches great importance to the development of graduate education and the cultivation of graduate innovation ability.

In recent years, the expansion of graduate enrollment in China continues to expand, however the serious quality challenges exist together with. Although many colleges implement the policy of "wide Admission and strict graduation" in postgraduate training programs, however, the lack of innovation ability of most postgraduate students is still outstanding. How to improve the innovation ability and level of graduate students and play the role of the reserve army of national scientific and technological innovation has become an urgent problem to be solved in China's graduate education.

After the proposal of "Deepening industry-education integration and university-enterprise cooperation" in the report of the 19th National Congress of the Communist Party of China. In the National Graduate Education Conference in 2020, Premier Keqiang Li also proposed to promote the integration of science and education as well as industry-education integration, focusing on cultivating graduate students with good practical and innovative ability, and providing more solid talent support for building a modern socialist country

It is an effective measure for the comprehensive reform of graduate education in colleges to deepen industryeducation integration and achieve the organic combination of the supply side of high-level innovative talents training and the demand side of high-capacity industrial and technical talents training. It is also an effective way for graduate education to integrate into the national innovation system and cultivate innovative talents for the country.

\section{CONNOTATION OF INDUSTRY- EDUCATION INTEGRATION}

"Industry-education integration", as its name implies, refers to the combination and integration of industry and education. Why has the Chinese government emphasized industry-education integration all the time? This reflects a contemporary problem in China's higher education and employment, that is, at present, China's industry and education are not integrated enough, they need to be further combined to achieve the effect of mutual promotion and interdependence. At present, there is a very contradictory phenomenon in Chinese society. On the one hand, there is an oversupply of "ineffective talents" cultivated by colleges, while on the other hand, enterprises are not satisfied with the "useful talents" they need. In theory, superfluous people in colleges and lack of people in companies, seems to can achieve a balance between supply and demand, but the reality is not. The superficial reason is that the "talents" who are not equipped with practical innovation ability cultivated by colleges and universities can not meet the needs of enterprises. The underlying reason is that "industry" and "education" are like two parallel lines without intersection. The goal of industry- 
education integration is to integrate "industry" and "education" and promote the organic connection between education chain and industrial chain.

As early as 1906, the University of Cincinnati put forward a novel lecture mode -- the "cooperative education" mode of paid internship, that is, universities and enterprises cooperate to cultivate students together, which is regarded as the beginning of the joint training mode of industry and education integration in modern higher education. Since then, various countries have copied this model, whose characteristic is the combination of learning and work[1]. Bektaş[2]pointed out that cooperation between university and industry can facilitate the transfer of knowledge and even stimulate the production of new knowledge and technology. Bekkers[3]pointed out that industry-education integration refers to the exchange and integration of knowledge, technology and resources between universities and enterprises, so as to cultivate talents jointly with highlevel technologies for enterprises. Later, Michael and Shanthi[4]added the connotation of industry-education integration. He believed that the participants of industryeducation integration should not be limited to enterprises and universities, other groups should join in, such as governments, social organizations and industry groups. The participation of more stakeholders breaks the resource, information and technical barriers that may exist in one-toone relationship under the original system, speeds up the deep integration of various elements of both parties or multiple parties, it is useful for integrating more resources and cultivating all-round talents. It can be said that the collaborative promotion of multiple subjects is the distinctive feature of the cultivation mode of industryeducation integration.

In China, "industry-education integration" was first used in vocational education, aiming to improve students' practical ability and adapt to future work needs earlier and faster. It is more like a kind of pre-employment training. Later, "industrial convergence" was gradually applied to undergraduate education and graduate education.

\section{THE REALISTIC DILEMMA OF INDUSTRY-EDUCATION INTEGRATION}

After years of exploration and practice, the integration of industry and education in Chinese universities has achieved some success. However, due to some constrains, many problems appeared. Industry-education integration has not been able to get a breakthrough, and the actual utility of industry-education integration has not achieved significant growth.

\subsection{The Depth of Industry-Education Integration is Insufficient}

School-enterprise cooperation, which is established between schools and enterprises, is the core content and important form of industry-education integration.
However, at present, most school-enterprise cooperation is still in the stage of low level and loose management. In addition, in school-enterprise cooperation, the phenomenon of "unrequited love" of schools is quite obvious. " Enterprises are indifferent, while Schools are enthusiastic". Enterprises behave negatively and formalismly in the cooperation with schools, and do not really consider their own planning to carry out in-depth exchanges with schools. In their opinion, the benefits from poaching graduates are more direct than those from cooperating with schools. For some enterprises, the enthusiasm to invest in higher degree of school-enterprise cooperation would vanish due to the lack of obvious profit enhancement, the lack of sufficient symmetric information, the lack of cooperation dominance, the lack of financial policy support and other reasons.

Under the influence of the negative emotions, some companies are reluctant to provide the latest and state-ofthe-art equipment to their cooperative school, what is more, they are not willing to appoint the core staff to the school to do some guidance, thus, students can only do some simple work which doesn't have technical content when they go to the cooperative enterprise do some practice. In a word, therefore it is more difficult to learn latest and useful skills. Because of this reason, the school also lost the initiative, just organize students to visit as a formality. This creates a vicious circle. School-enterprise cooperation, which should have benefited both sides, has now become a superficial exchange program of signing cooperation agreements relying on human relations, without really integrating industry and education into the whole process of talent cultivating.

\subsection{The Relative Disconnection between Industry and Education}

In the process of promoting industry-education integration, due to the lack of in-depth participation of enterprises, many colleges and universities seem to have lost their direction when cultivating students. The setting of curriculum content are often deviated from the practical production line, and the teaching content of colleges and universities does not match the production reality, resulting in the relative disconnection between industry and education.

It is still a very common phenomenon that the proportion of theory courses is too large, and the teaching experiment, professional practice and other practical courses take up too little time. Even if some schools increase the number of practical teaching courses and increase the number of practical teaching hours, it seems that the professional setting is "large and complete", but due to the lack of indepth communication with enterprises, there will still be divorced from the actual production, behind the development of science and technology. There will be no quality assurance for the course.

On the other hand, there are also many problems in the construction of teachers and the equipment for experiments. Although the problem of attaching more 
importance to scientific research than practice has been improved, most teachers have been accustomed to the traditional teaching mode in the past, and it is difficult to transform under the circumstance of technological upgrading and professional replacement. Schools also lack the overall transformation training of teachers, so the teachers can not keep up with the needs of practical teaching. In addition, the lack of experimental scenes and equipment involved in industry-education integration makes it difficult for students to develop excellent practical and innovative abilities.

In this case, the professional skills, practical ability and innovation consciousness of college students cannot match the job needs of employers, which is the industry-education disconnection at the employment level caused by the industry-education disconnection at the teaching level.

\subsection{The Mechanism and Policy of Industry- Education Integration are not Perfect}

As mentioned above, it is our goal to promote industryeducation integration through the coordination of multiple subjects. However, in reality, due to the various subjects involved in industry-education integration, such as universities, enterprises, governments, financial institutions and social organizations, their social attributes and functions are different, and their organizational structures and operation modes are also different. Subsequently, there would be some conflicts of opinion, such as economic with public welfare, stability with risk and so on.

At present, each main subject can only do its own job at most, far from achieving a coordinated development pattern. The management between each subject is scattered, lacking integrity and systematicness. Information sharing channels, incentive mechanism, benefit distribution mechanism, cooperative relationship guarantee mechanism are all not perfect.

Because the system of industry-education integration has not been formed and there is no perfect organization, the awareness of the rights and responsibilities of the relevant subjects is often not clear enough. They can't clear their responsibility and obligation, and it is difficult to balance the reasonable demands of all participants. They often have different interpretation of the policy on its own situation for their respective interests. to some extent those would affect the efficiency of integration and destroy cooperative relationship. On the other hand, the current specific policies are more about "encouragement", "support" and "try", and lack of policy promotion of high value. This also indirectly leads to the lack of enthusiasm for the participation of various subjects, the lack of close coordination among all parties and the low actual results.

\section{NECESSARY MEASURES TO DEEPEN INDUSTRY-EDUCATION INTEGRATION}

Only by reconstructing the organization structure of industry-education integration, making all parties benefit from it, can all participants arouse their enthusiasms. And only in this way, can industry-education integration be deepened.

\subsection{To Improve Organization and Policy System}

To deepen industry-education integration, we must complete and implement relevant policies and legal systems. Make the policy really implemented that was only on the lips or on the paper previously. In this way, the government's determination to deepen the implementation of policies on industry-education integration can be felt by universities, enterprises and social organizations.

We will introduce detailed rules for the implementation of fiscal, taxation and financial policies, strengthen fiscal, tax and financial support, guide the participation of various nongovernmental capital, and constantly expand other channels for financial investment, so that universities and enterprises will not give up simply because of economic problems. Relevant laws and regulations are issued to regulate the behavior of each participant, and the responsibilities they must bear and corresponding preferential policies they can enjoy are clearly defined. We will continue to improve the business environment, improve the efficiency of government services, overcome information asymmetry among enterprises, and make industry-education integration more efficient.

By constantly improving the mechanism and supporting policies, the initiative of each subject in industry-education integration would be spurred to promote the close combination of various subjects and constantly deepen industry-education integration.

\subsection{To Improve the Comprehensive Evaluation System}

It is an effective means to establish a comprehensive evaluation system for industry-education integration. Finding defects and loopholes from evaluation is also the internal requirement of perfecting the mechanism of industry-education integration.

From the perspective of the government, a scientific comprehensive evaluation system for industry-education integration can effectively evaluate and test the specific implementation of school-enterprise cooperation in industry-education integration. Comprehensively understand the progress and development status of industry-education integration, form institutionalized and standardized dynamic evaluation, timely find and solve problems in the implementation process of industryeducation integration, ensure the quality of industryeducation integration, promote the coordinated development of universities and enterprises, and achieve the synchronous improvement of talent training and industry progress. 
From the perspective of colleges and universities, the evaluation is mainly carried out from the professional title evaluation, training quality, employment situation and other aspects. The teaching practice design, enterprise cooperation results and postgraduate training results in the process of industry-education integration will be incorporated into the professional title selection system of teachers, and the evaluation system of industry-education integration will be improved. Evaluate the effect of industry-education integration from the perspective of improving students' innovation and practice ability and employment situation.

In addition, a third-party evaluation system will be introduced to give full play to the important role of multiple stakeholders such as industry associations and social organizations in the evaluation system, so as to build an industry-education integration evaluation system with the participation of multiple subjects.

A good operation guarantee mechanism cannot be separated from a perfect evaluation system. Establishing a comprehensive dynamic evaluation system for industryeducation integration is a guarantee to improve the effect of industry-education integration and the quality of talent training.

\subsection{To Highlight the Important Role of Enterprises}

Facing the phenomenon of "enterprise cold", industryeducation integration needs to highlight the important role of enterprises to a certain extent.

First, lower the threshold for enterprises to participate in industry-education integration, expand the channels for enterprises to participate in industry-education integration, absorb some potential private capital enterprises and weak enterprises into industry-education integration, and give enterprises more freedom of cooperation.

Second, support enterprises to deeply participate in the university teaching reform of the industry-education integration project. From tutor training, teaching and courses, dissertations and other aspects, more enterprises should be involved. Implement the talent cultivation mechanism of "the whole process of dual tutors" [5], the use of engineering alternation training mode, support the school teacher to study enterprise exercise regularly, and regularly to mentor to examine the level of innovation, cooperation, contribution, and the innovative academic achievements as a tutor assessment is an important index, with outstanding cooperation, the innovation breakthrough mentors give corresponding reward, Encourage more innovative collaboration and research by mentors. With the deepening of the integration of industry and learning, it is necessary to add enterprise factors into postgraduate training programs and curriculum, and keep pace with the constantly updated and innovative production technology. In the topic selection of graduate thesis, we should also focus on practicability, take the actual needs of enterprises as an important source of topic selection, and connect with the forefront of discipline and production.

Third, we should promote collaborative innovation through multi-party cooperation and solve technological bottlenecks in enterprises' actual production. Universities, research institutions, industry organizations and other forces should be pooled to build cooperation platforms to help enterprises innovate.

Encourage and support enterprises to invest more in industry-education integration through these measures taken simultaneously, give consideration to social benefits and corporate benefits, and focus on solving the problem of enterprises' low enthusiasm for participation. Only in this way can we better implement industry-education integration in order to improve the efficiency of talent training.

\section{CONCLUSION}

Deepening industry-education integration requires the joint efforts and coordination of the government, enterprises, universities and industry organizations[6]. Only by integrating industry and education into practice, can colleges and universities cultivate talents needed by enterprises and society. And the huge contradiction in the employment market that the supply of "ineffective talents" in colleges and universities is excessive while enterprises can not get the "useful talents" they want can be solved. Industry-education integration is not only the fast way to industrial transformation and upgrading, but also the way to do a good job in educational reform. In this era innovation determines the future, graduate education in colleges and universities should cooperate with enterprises through industry-education integration. Have a keen insight into the direction of technological innovation, scientific and technological progress and productivity development from the perspective of the industry. Only in this way can more innovative and creative talents be cultivated to realize the dream of innovation and help the motherland take off.

\section{ACKNOWLEDGMENT}

This research was financially supported by the Jiangxi Province Degree and Postgraduate Education Reform Research Project, "Research on the Cultivation of Postgraduate Innovative Ability in Transportation Discipline Based on the Integration of Production and Education".

\section{REFERENCES}

[1] BLAIR B F, MILLEA M, HAMMER J. The impact of cooperative education academic performance and compensation of engineering major[J]. Journal of engineering education, 2004, 93(4): 333-337. DOI: 10.1002/j.2168-9830.2004.tb00822.x 
[2] Çetin Bektaş, Gulzhanat Tayauova, A Model Suggestion for Improving the Efficiency of Higher Education: University-Industry Cooperation, Procedia Social and Behavioral Sciences, 2014, 116: 2270-2274. DOI: https://doi.org/10.1016/j.sbspro.2014.01.558

[3] BEKKERS R, BODAS FREITAS I M B. Analysing knowledge transfer channels between universities and industry: to what degree do sectors also matter? [J]. Research policy, 2008, 37(10): 1837-1853. DOI: https://doi.org/10.1016/j.respol.2008.07.007

[4] SANTORO M D, GOPALAKRISHNAN S. The institutionalization of knowledge transfer activities within industry-university collaborative ventures $[\mathrm{J}]$. Journal of engineering and technology management,
2000, 17(3/4):299-319. DOI:

https://doi.org/10.1016/S0923-4748(00)00027-8

[5] Minghui Qian, Jialu Guo, Jing Qin. The Integration Model of Production and Education for MLIS in China: Types, Problems and Suggestions[J/OL]. Library Tribune:1-11[2021-12-10]. DOI:

http://kns.cnki.net/kcms/detail/44.1306.G2.20211207.13 35.004.html (in Chinese)

[6] Weidong Yan, Sujun Wang, Wenhao Lv. he Logical Analysis and Path Selection for Promoting Local Colleges and Universities'Connotation Development by Production and Education Integration [J]. Modern Education Management, 2021, 6: 44-50. DOI: https://doi.org/10.16697/j.1674-5485.2021.06.006 